\title{
Expert's Usability Evaluation of the Pelvic Floor Muscle Training mHealth App for Pregnant Women
}

\author{
Aida Jaffar ${ }^{1}$, Sherina Mohd Sidik $^{2 *}$, Novia Admodisastro ${ }^{3}$, Evi Indriasari Mansor ${ }^{4}$, Lau Chia Fong ${ }^{5}$ \\ Faculty of Medicine and Health Sciences, Universiti Putra Malaysia, Serdang, Selangor, Malaysia ${ }^{1,2}$ \\ Faculty of Medicine and Defence Health, Universiti Pertahanan Nasional Malaysia, Kuala Lumpur, Malaysia ${ }^{1}$ \\ Faculty of Computer Science and Information Technology, Universiti Putra Malaysia, Serdang, Selangor, Malaysia ${ }^{3}$ \\ Abu Dhabi School of Management, Abu Dhabi, United Arab Emirates ${ }^{4}$ \\ Faculty of Science, Universiti Malaya, UM, Kuala Lumpur, Malaysia ${ }^{5}$ \\ PeonTech Solutions, Petaling Jaya, Selangor, Malaysia ${ }^{5}$
}

\begin{abstract}
Pelvic floor muscle training (PFMT) is the first line in managing urinary incontinence. Unfortunately, personal, and social barriers involvement hinder pregnant women to perform PFMT. Therefore, a Kegel Exercise Pregnancy Training (KEPT) app was developed to bridge the accessibility barriers among incontinent pregnant women. This study aimed to evaluate the usability properties of the KEPT app developed for pregnant women to improve their pelvic floor muscle training. A purposive sampling method of the experts was conducted from a sample of experts in informatics and a physician with a special interest in informatics. The design activities were planned in the following sequence: cognitive walkthrough for learnability of the app, heuristic evaluation for the interface of the app and usability questionnaire to evaluate the usability properties (quantitative assessment) of the app. The mHealth application usability questionnaire (MAUQ) was used as its assessment tool to assess the application usability. A total of four experts were involved in this study. Cognitive walkthrough revealed that the KEPT app has several major learnability issues especially the training interface and language consistency to ensure its learnability. Heuristic evaluation showed that the training interface must provide additional information regarding the displayed icon. KEPT app was rated by MAUQ being as ease-of-use, the interface and satisfaction with the usefulness by all the experts which scored 5.80/7.0, 5.57/7.0, and 5.83/7.0, respectively. The suggestions were shared to assist future researchers and developers in developing PFMT mHealth app.
\end{abstract}

Keywords-Pregnant women; pelvic floor muscle training; mHealth app; usability evaluation; cognitive walkthrough; heuristic evaluation

\section{INTRODUCTION}

Urinary incontinence (UI) is an involuntary urine leakage [1]. UI commonly occurs about $40 \%$ among pregnant women and negatively affects their quality of life [2-4]. Unfortunately, despite UI affecting their daily activities, only one-tenth of pregnant women seek help due to the misperception that UI would resolve by itself [5]. Therefore, correct information on UI and its management by performing regular pelvic floor muscle training (PFMT) should be available for pregnant women.
However, there were barriers in delivering the PFMT health information to pregnant women. The issues such as healthcare providers focusing on a higher priority medical illnesses in pregnancy or antenatal services midwives have busy workloads in a service structure hindrance the health education to pregnant women [6]. Additionally, pregnant women tend to normalize and perceived that the incontinence is normal during pregnancy and will disappear after the delivery of their baby [7]. An alternative method in delivering health education is needed to educate pregnant women effectively according to their time and their availability.

Recently, smartphones gaining its popularity and has become a daily used items the most popular mobile technology. People tend to multitask using their smartphones seeking the information through smartphone applications conveniently. Additionally, they were able to search and confirm information while they use various other media or smartphone applications simultaneously [8]. The multitasking element enable the mobile health app becomes trending nowadays. Mobile health (mHealth) apps have been shown to be one of the rising in literature in sharing health information and education across several diseases. Unfortunately, mHealth apps demonstrated weak evidence in its effectiveness which may be improved in the evaluative approaches to the development and assessment of the health care improvement apps [9].

Motivation of this research is to conduct a rigor evaluation on the development of the app to ensure the usability and its effectiveness. This study aims to evaluate a newly developed mHealth application (Kegel Exercise Pregnancy Training or KEPT app) which was designed and developed to improve the delivering pelvic floor muscle strength health education to pregnant women. The specific objectives of the study are:

1) To understand the heuristic evaluation, cognitive walkthrough, and usability evaluation of the KEPT app from the experts' evaluation.

2) To suggest the improvement for the KEPT app for better usability.

*Corresponding Author 


\section{RELATED WORK}

\section{A. PFMT and Pregnant Women}

PFMT or Kegel exercise is an important exercise among pregnant women to strengthen their pelvic floor muscles [10], which enables them to prevent UI during their advance trimester and early postpartum period [11]. Despite having good knowledge of PFMT, the practices are still low [4]. This finding suggests that incontinent pregnant women with good PFMT knowledge are not practicing PFMT or those practicing PFMT may be less likely to perform it correctly. Pregnant women need to tailor the PFMT according to their schedules to improve its adherence.

There are a few hiccups in delivering PFMT to the pregnant women at the primary care clinics in this country. There was a dedicated physiotherapist scheduled monthly in certain clinics and for some clinics, the selected pregnant women met in a group session once or twice per year. Unfortunately, these sessions could be troublesome for some pregnant women who are busy managing their family and work at the same time. Furthermore, with the current COVID-19 pandemic, the number of daily attendances has been reduced to avoid the crowdedness in the clinic and abide with the social distancing protocol. Therefore, a carefully designed digital health intervention (mHealth app) has the potential to disseminate PFMT and improve the adherence of these women to manage their UI especially among primigravida with stress UI [12].

\section{B. Expert Evaluation}

To ensure the quality of mHealth app, usability concept or assessment need to be assessed $[13,14]$. Usability evaluation or inspection is the generic name for a set of cost-effective ways of evaluating user interfaces to find usability problems [15]. Usability is defined when an app can be well understood, easily operated and has its unique attraction to the users in order to accomplish certain tasks in specific environments [16,17]. Hence, usability is also mentioned as being feasible and acceptable to be effective in changing mHealth lifestyle [18].

Nielsen explained that there are four basic ways in evaluating user interface such as via automatically (usability measures computed by running a user interface specification through some program), via empirically (usability assessed by testing the interface with real users), via formally (using exact models and formulas to calculate usability measures), and informally (based on rules of thumb and the general skill and experience of the evaluators) [15].

Additionally, the recruitment sampling of the experts is crucial whereby the experts can be either the academician with software design (mobile application) or clinician with a special interest in mobile apps who are not from the researcher's team as the usability evaluators. Three to five experts are recommended for the usability testing for heuristic evaluation (user interface) in major issues detection [19]. In this study, we will focus on three types of usability evaluations: cognitive walkthrough, heuristic evaluation, and usability testing.

\section{Cognitive Walkthrough (CW)}

Cognitive walkthrough $(\mathrm{CW})$ by the experts were evaluated on the difficult task to add more depth for critical assessments [20]. CW utilizes accurate detailed procedures to simulate a user's problem-solving process at each step through the dialogue or user interface, to study whether the simulated user's goals and memory content can be assumed to direct the users to perform the next correct action [15].

To assist the experts, a persona is used for them to understand the user's characteristics and literacy in using the mobile application. Persona is defined as, "memorable representations of users that remain conspicuous in the minds of those who design and build products" [21]. Persona consists of specific facts, has a concrete representations of target users, which in this study is pregnant women. Persona is constructed in an engaging, and actionable image which provides as a design target. Persona's main role is to assist the experts to be more user focused.

The users, being complicated and varied took great effort to be understood with their health conditions, needs, and behaviors. The experts who were not from the users' socioeconomic background faced difficulties to imagine and understand the users' behavior and challenges using the app. Without preliminary informative such as persona, it is more likely the experts imposed their assessment based on their own perspective and not from the users'. If the researcher and developer proceed with these findings, it will be a non-user centered app which may affect the users' involvement and jeopardize their targeted behavior changes.

\section{Heuristic Evaluation (HE)}

There are challenges in creating mobile learning applications since smartphones or mobile devices built-in with small screen size, small memory, lack of input capability, and limited processing power [22]. Nielsen (1994) proposed ten heuristic evaluations to detect user interface problems costeffectively: a) visibility system status; b) system matched with real world; c) user control; d) consistency; e) error prevention; f) recognition than recall; g) flexibility; h) aesthetic and minimalist; i) learning retention; and $\mathrm{j}$ ) documentation.

Additionally, Kumar and Goundar (2019) added three new heuristics assessment for mobile learning applications. This is because, smartphone has limited function such as the small screen, despite its almost always accessible. The assessments included were: a) selection driven commands; b) content organization; and c) visual representation [23].

Furthermore, the mobile applications included health intervention. Hence, to further assess the heuristic element in this study, Khowaja and Al-Thani (2020) suggested a questionnaire which is called "Heuristic Evaluation of mHealth Apps (HE4EH)" to be used. HE4EH consisted of 25 checklist items, where the most relevant to this study were the selfmonitoring and behavioral change items to evaluate the interface according to its objective [24]. 


\section{E. Usability Questionnaire $(U Q)$}

There were a few validated questionnaires which can be used to evaluate the usability of an app, for example, the System Usability Scale (SUS) [25], and Post-Study System Usability Questionnaire (PSSUQ) [26]. However, a recent usability questionnaire has been developed and validated to assess usability of an mHealth app which is called the "mHealth App Usability Questionnaire (MAUQ)" [27] which has three domains focusing on the ease of use, interface and satisfaction, and usefulness of the mHealth app [27].

SUS is a ten-item questionnaire using a Likert scale, which assess a global view of usability assessments. The aim was to obtain a quantitative assessment, which was conducted based on general agreement that the evaluated system was "really easy to use". The user must be given a chance to use the "system" in the first place. After that, the user must assess the "system" using SUS before any debriefing session. The user is required to record their immediate response to each item without any hesitancy [25].

PSSUQ indicated a 3-factor structure consistent with usability that initially described factors for System Usefulness, Information Quality, and Interface Quality. This questionnaire was used to assess the user satisfaction after participation in a scenario-based usability [28]. The 18 questions-assessment was based on a seven-point Likert scale from "Strongly agree" for 1 and "Strongly disagree" for point 7. However, these two usability questionnaires were not specifically designed for the mobile health app usability.

Hence, recently, a usability questionnaire has been developed and validated to assess 18-usability properties for the mobile Health app which is called as mHealth App Usability Questionnaire (MAUQ) [27].

\section{KegEl EXERCISE PREgNANCY TRAINING APP}

Kegel Exercise Pregnancy Training (KEPT) app was developed from a combination of Persuasive Techniques and Capability, Opportunity, Motivation-Behaviour model. It was developed using Interviewing Mapping which embedded in a user-centered design using UCD-11 framework [29]. KEPT app runs on Android platform only.

This KEPT app encouraged pregnant women to train their pelvic floor muscle according to their daily schedule and individual capability. It has five user interfaces; (1) educational video - to deliver the PFMT training sessions (Fig. 1), (2) calendar charting for user interface UI symptoms, (3) training mode stopwatch assistance, (4) progress chart to self-monitor progress, and (5) Frequently Asked Question (FAQ) for information sharing regarding correct method in PFMT.

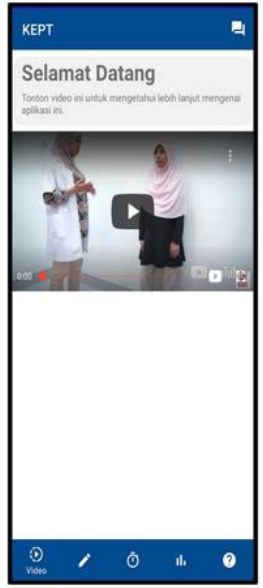

(a)

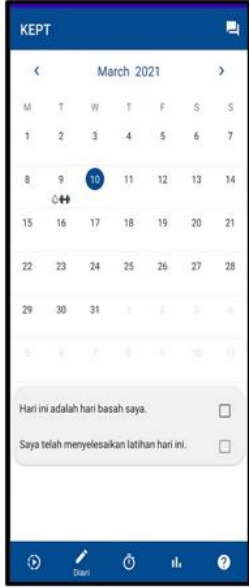

(b)

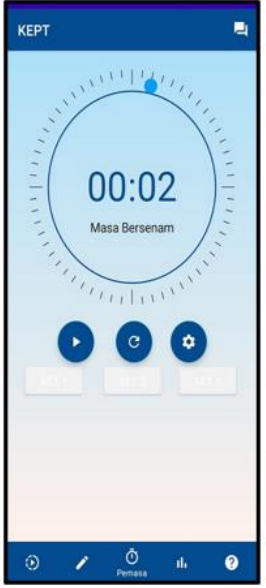

(c)
Fig. 1. Some of the KEPT App user Interfaces (a) Educational Video; (b) Calendar Charting; (c) Timer Exercise.

\section{METHODS}

The ethical approval was obtained from Ethics Committee for Research Involving Human Subjects, Universiti Putra Malaysia (JKEUPM-2019-368) and Medical Research and Ethics Committee (MREC), Ministry of Health Malaysia (NMRR-19-412-45606) before the commencement of the study.

\section{A. Expert Evaluation}

A total of six academics and one from the industry were invited as experts of the study. However, only four academics were agreed to become the experts in this study as listed in Table I. The study was conducted at their own time allocated and their own place.

The experts were required to evaluate the application in three sections; (a) cognitive walkthrough; (b) heuristic evaluation; and (c) usability questionnaire (Fig. 2).

TABLE I. EXPERT'S LIST

\begin{tabular}{|l|l|l|l|}
\hline ID & $\begin{array}{l}\text { Age and } \\
\text { Gender }\end{array}$ & Ethnicity & Experts \\
\hline E1 & $44 /$ Female & Malay & $\begin{array}{l}\text { Senior Lecturer, Centre for Software } \\
\text { Technology and Management, Public } \\
\text { University }\end{array}$ \\
\hline E2 & $41 /$ Male & Malay & $\begin{array}{l}\text { Associate Professor, Science and } \\
\text { Technology System, Public University }\end{array}$ \\
\hline E3 & $42 /$ Female & Chinese & $\begin{array}{l}\text { Associate Professor, Department of } \\
\text { Family Medicine, Public University }\end{array}$ \\
\hline E4 & $44 /$ Female & Malay & $\begin{array}{l}\text { Associate Professor, School of } \\
\text { Multimedia Technology and } \\
\text { Communication Educational } \\
\text { Multimedia, Public University }\end{array}$ \\
\hline
\end{tabular}




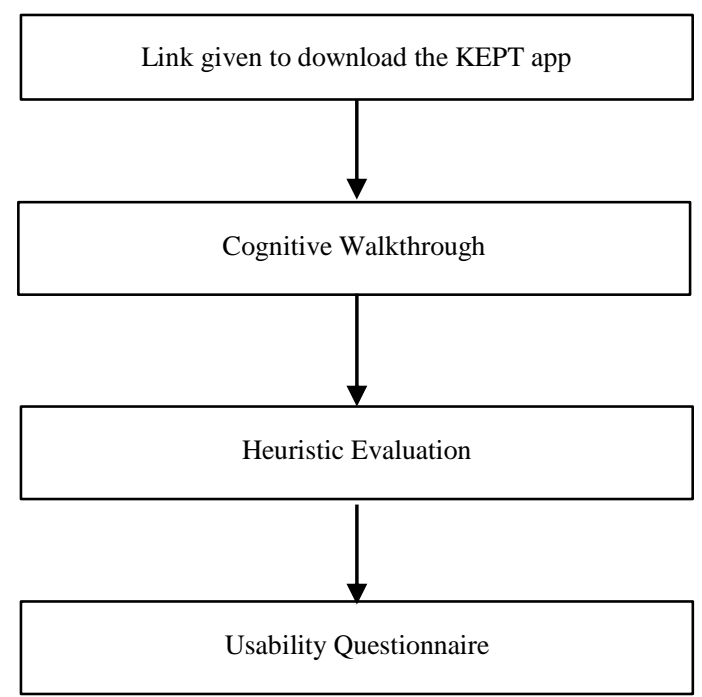

Fig. 2. Expert Evaluation Tasks.

\section{B. Cognitive Walkthrough $(\mathrm{CW})$}

At the beginning of the session, a persona was introduced to the expert which was adopted from the previous study (Jaffar et al., 2020) to help the expert to understand the situation of a pregnant woman's experience of urinary incontinence as below.

- Background. Mrs Aida, a 38-year-old housewife, has a history of being unable to control her urination (urinary incontinence) for a month. She is currently pregnant (unplanned pregnancy but wanted), with her fifth pregnancy at 34 weeks.

- Medical condition. Mrs Aida has anaemia in all pregnancies, including this current pregnancy. She sometimes skipped her meals as she had no time to have lunch and suffered from gastritis.

- Psychological. Mrs Aida is stressed about her current pregnancy as she is having incontinence and busy managing her family. She felt tired quickly and suffered poor sleep. In the morning, Mrs Aida needs to prepare breakfast and rush to send her kids to school and manage house chores. She has to take care of her 12year-old son, 10-year-old girl, 9-year-old son and 8year-old-son.

- Level of health literacy. Mrs Aida does not know about urinary incontinence, and she thought it is "normal" during the pregnancy period and during post-natal.

- Social. Her husband is a technician and is seldom at home as he has another job (Grab-food delivery) to support the family.

- Technological literacy. Mrs Aida used her handphone to make phone calls, WhatsApp, and recently online meeting platform for her children's online schooling using her mobile data. She does not have any social media apps. She claims she has no time to use her phone and only uses her phone to make a call only or for her children's school activities.
- Relationship with healthcare providers. She has a good relationship with them and will try her best to follow their advice. She received a food basket from the clinic for her children as they have been diagnosed with malnourishment.

- Information preferences. Mrs Aida prefers watching videos, especially when it involves an expert. Unfortunately, her educational status was until secondary school, and she could not absorb too much information at one time.

- Current issue. Mrs Aida just downloaded the "Kegel Exercise Pregnancy Training” app (KEPT app) as she seriously wants to control her urination. She is very busy managing her daily chores and does not have time to go for a physiotherapist appointment. She hopes that using this app can help her remind her of the exercise (despite her busy daily schedule) and manage her urinary incontinence.

After understanding the persona, experts were required to interact with the application and performed the following tasks: (a) to sign-up; (b) to watch the video; (c) to do charting (selfmonitoring); (d) to perform PFMT; (e) to submit feedback; and (f) to log out the app.

Then, experts were asked to evaluate the application based on the following criteria: (a) major issues - important to fix with high priority; (b) minor issues - to fix the problem with low priority; and (c) no usability issues - may fix if time is available.

\section{Heuristic Evaluation (HE)}

During the heuristic evaluation session, experts were asked to rate the interfaces of the application based on 15 items. The first ten questions were based on Nielsen (1994) and adopted by Kumar et al., (2019), the next three questions emphasized on the mobile learning by Kumar and the last two questions were adopted from mobile health apps evaluation by Khowaja et al., (2020) which focus on the behavioral changes and selfmonitoring $[15,23,24]$. The experts assessed the interface using the given rating-scale: [1] to denote a usability disaster; [2] a major problem; [3] a minor problem; [4] a superficial problem; and [5] not a problem at all [23].

1) Ten-Heuristic [15]:

- Visibility of the system status whereby the user was given the appropriate feedback.

- Match between the system and real world which enable users to identify the elements of the application.

- User control and freedom that allowing the users to go different menus easily.

- Consistency and standards to ensure the consistency of the application.

- Error prevention whereby the users can recover from their errors.

- Recognition rather than recalls minimizing the user' $\mathrm{s}$ memory load while using the apps. 
- Flexibility and efficiency of use whereby the app can be adjusted by anyone.

- Aesthetic and minimalist design by removing the unnecessary information.

- Help users recognize, diagnose, and recover from errors to allow user' s learning retention.

2) Mobile learning (Kumar \& Goundar, 2019):

- Help and documentation whereby the app can assist the users in learning.

- Selection driven commands whereby the users engage with the apps.

- Content organization as the app can highlight the key objectives.

- Visual representation on the usage of the icons to assist the users understanding.

3) Mobile health app (Khowaja \& Al-Thani, 2020):

- Behaviour changes included the app's design that gradually starts with easy tasks, until target behavior is performed.

- Self-monitoring with several specific steps to selfmonitor their expected outcomes.

\section{Usability Questionnaire}

Finally, all experts were instructed to answer a set of questions which covered three main domains such as, the ease of use, interface and satisfaction, and the usefulness of mHealth apps using the mHealth App Usability Questionnaire [27]. The experts rated each of the items using a 7-point Likert scale ranging from 1 (strongly disagree) to 7 (strongly agree).

Zhou et al (2019) listed three main domains for usability assessment in mHealth app which are ease of use (5 questions), interface and satisfaction (7 questions), and usefulness (6 questions). The overall Cronbach alpha was 0.932, which scored $0.895,0.829$, and 0.900 , for ease of use, interface and satisfaction, and usefulness, respectively.

All participants' names were replaced with an identification code. The CW reports were extracted from the word documents. The feedback from the experts was analyzed based on the severity of the issues. The suggestions were then reported, and the clarification was made directly to the experts for better understanding.

HE and UQ data were analyzed descriptively using the SPSS 26.0 to report the mean, median and standard deviation. Similarly, the suggestions from the experts have been recorded.

\section{Results}

\section{A. Cognitive Walkthrough $(C W)$}

The experts listed a few major issues from the cognitive walkthrough method with the most major issue being the training interface. Training PFMT had four major issues which signified the lack of clarity and self-explanation of the training section. However, there was heterogeneity of the assessments by the experts whereby E4 detected more major issues compared to others while E2 detected the least issues. The compilation of the reports as listed in Table II.

TABLE II. COGNITIVE WALKTHROUGH

\begin{tabular}{|c|c|}
\hline Task & Issues and recommendation \\
\hline To sign-up & $\begin{array}{l}\text { E1: Major Issue: Font on registration text boxes (active } \\
\text { boxes) faded. Difficult to read. } \\
\text { Recommendation: Change active text box font colour. } \\
\text { E2: Cosmetic: Good and clear instruction } \\
\text { E3: Minor issue: The (!) mark at the end of the email } \\
\text { address said invalid email address. } \\
\text { Recommendation: } \\
\text { 1.The comment should read "Awaiting admin approval" } \\
\text { instead of "invalid email address". If the app is in Malay, } \\
\text { the comments should be in Malay as well. } \\
\text { 2.Add a checkbox for the app to remember login details for } \\
\text { users who have problems with remembering passwords. } \\
\text { 3. Guided tutorial for new users on identifying the main } \\
\text { sections of the app. } \\
\text { E4: Major issues: } \\
\text { (a) Create account, The instruction was not functioning/ } \\
\text { clickable } \\
\text { Recommendation: Need to fix or omit the function as it } \\
\text { will not mainly affects the registration form } \\
\text { (b) Patient Information Sheet Instruction was not given on } \\
\text { how to use the KEPT apps. } \\
\text { Recommendation: Need to give a user manual via video } \\
\text { demo on how to use/operate the KEPT apps. The given } \\
\text { video was about to educate the Kegel Exercise demo but } \\
\text { not on the KEPT apps itself. }\end{array}$ \\
\hline The video & $\begin{array}{l}\text { E1, E2 and E3: Cosmetic problem only } \\
\text { E4 Major issue: } \\
\text { (a)The physiotherapist was mentioned about "imagine the } \\
\text { muscle contraction as eating the spaghetti" in the video but } \\
\text { the FAQ did not mention this. } \\
\text { Recommendation: To consistently use terminology with } \\
\text { the physiotherapist in the FAQ. } \\
\text { (b)The name of the app was provided in the English } \\
\text { acronym as KEPT (Kegel Exercise Pregnancy Training) } \\
\text { but the main language used in the apps is in Bahasa } \\
\text { Malaysia. } \\
\text { Recommendation: It is recommended to standardize in } \\
\text { using only one language -Bahasa Malaysia due to the main } \\
\text { language used in this apps is in Bahasa Malaysia }\end{array}$ \\
\hline $\begin{array}{l}\text { The charting } \\
\text { (self- } \\
\text { monitoring) }\end{array}$ & $\begin{array}{l}\text { E1, E2 and E3: Cosmetic problem only } \\
\text { E4 Major Issues: } \\
\text { (a)The language used was in English and reflects the } \\
\text { inconsistency issue. } \\
\text { Recommendation: Need to consistently use Bahasa } \\
\text { Malaysia instead of using mixed languages. } \\
\text { (b)The statement of "I have done the exercise today" was } \\
\text { not clickable. } \\
\text { Recommendation: Need to fix or omit the function based } \\
\text { on the functional requirement of the apps. } \\
\text { (c)The status of "total wet day" and "Total Day Completed } \\
\text { exercise" were confusing as not showing any status. } \\
\text { Recommendation: Need to omit the status based on its } \\
\text { confusion. }\end{array}$ \\
\hline
\end{tabular}




\begin{tabular}{|c|c|}
\hline The Training & $\begin{array}{l}\text { E1 and E2: Minor issue: Difficult to understand } \\
\text { E3: Minor Issue: The cogwheel icon is placed last in the } \\
\text { row of buttons. There is no description for its function, } \\
\text { which is to set the difficulty level. } \\
\text { Recommendation: Place the cogwheel icon first before the } \\
\text { play button. Label it as difficulty level. } \\
\text { E3 Major Issues: } \\
\text { (a)There is no explanation on the timer. Users may not } \\
\text { know that they are supposed to do the exercise while the } \\
\text { timer runs. Users cannot see how many times they have } \\
\text { done the exercise for each set. } \\
\text { Recommendation: Need to have instruction before start, } \\
\text { that this page is for the exercise. } 2 \text { second timer for ready, } \\
6 \text { second timer for contracting muscles. } \\
\text { Should have a counter to show completion of each set. } \\
\text { Example:1/6, } 2 / 6 \\
\text { (b)User does not know whether the exercise was done } \\
\text { correctly or not. } \\
\text { Recommendation: Tips or Cues on knowing whether done } \\
\text { correctly. Prompts to say you need to complete ... number } \\
\text { of sets to complete today's exercise. } \\
\text { (c)I am not sure of the function of the reset button. } \\
\text { Recommendation: Explanation on what the reset button is } \\
\text { for. } \\
\text { E4: Major issue } \\
\text { (a)Set } 1 \text {, Set } 2 \text { and set } 3 \text { menus were not functioning, and } \\
\text { also got typo error. } \\
\text { Recommendation: Need to fix or omit the function based } \\
\text { on the functional requirement of the apps. }\end{array}$ \\
\hline The Feedback & $\begin{array}{l}\text { E1- no issue } \\
\text { E2: Cosmetic problem only } \\
\text { Recommendation: More infographics to make interesting } \\
\text { E3: Cosmetic problem: A question mark icon usually } \\
\text { represents the help button in most apps. Here it is } \\
\text { representing the questionnaire. } \\
\text { Recommendation: Use the pen or notepad icon for } \\
\text { questionnaire instead of question mark. } \\
\text { E3 Minor issues: } \\
\text { (a)Users may not know when to fill in the questionnaire. } \\
\text { No reminder for the user of which timing to choose. } \\
\text { (b) If the user chooses the wrong timing, not sure of how to } \\
\text { get back to the main questionnaire screen. } \\
\text { Recommendation: } \\
\text { 1.Built in calendar tracking for the day of first use. } \\
\text { Reminder to fill in a questionnaire at time points from new } \\
\text { user registration. } \\
\text { 2. Add instructions to the user: To go back, tap on the } \\
\text { questionnaire icon again. } \\
\text { E4 Major Issue: There was no instruction given on that } \\
\text { page. The use of 'app' in the labelling was not suitable. } \\
\text { Recommendation: Need assistance or cue on what to do on } \\
\text { that page } \\
\text { Replace the 'app' with the name of the app }\end{array}$ \\
\hline The Logout & $\begin{array}{l}\text { E1, E3 and E4 Major Issue: I cannot find the logout button. } \\
\text { Recommendation: Logout button, account profile should } \\
\text { be visible somewhere. } \\
\text { Need to provide an exit/log in back widget in the app. }\end{array}$ \\
\hline
\end{tabular}

\section{B. Heuristic Evaluation}

Similarly, as the $\mathrm{CW}$, there was heterogeneity of the $\mathrm{HE}$ among the experts as illustrated in Fig. 3. The lowest score of user interface was the "visibility-provide feedback" which has been expected as this app is a standalone app without any direct communication to the healthcare providers. The highest user interface score was the behavior change element which highlights that the KEPT app was able to encourage the users to change their behavior in a real-world situation with the user's compliance. Therefore, the HE results may conclude that the KEPT app interfaces have been designed in an acceptable manner to assist the users' PFMT adherence as listed in Table III.

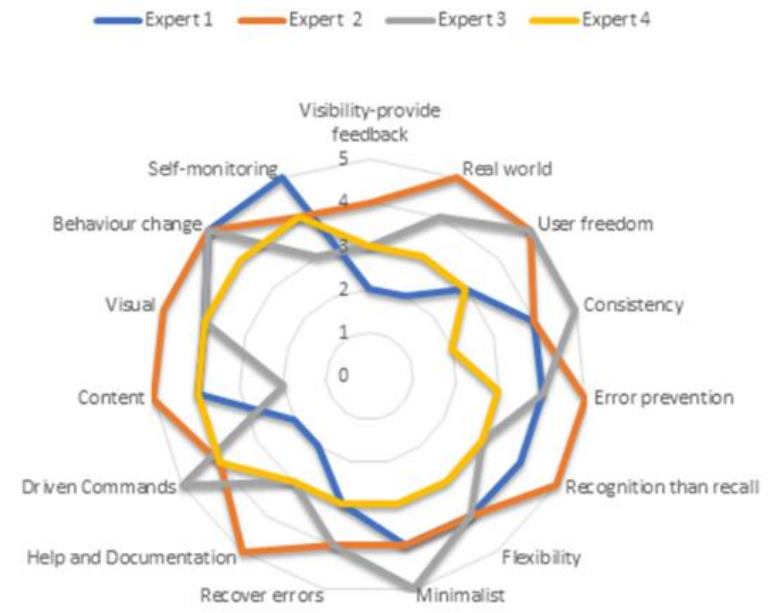

Fig. 3. Heuristic Evaluation Expert's overview.

TABLE III. HEURISTIC EvaluATION

\begin{tabular}{|l|l|l|l|}
\hline Heuristic assessment & $\begin{array}{l}\text { Mean } \\
\text { (SD) }\end{array}$ & Heuristic assessment & $\begin{array}{l}\text { Mean } \\
\text { (SD) }\end{array}$ \\
\hline $\begin{array}{l}\text { 1. Visibility of system } \\
\text { status }\end{array}$ & $\begin{array}{l}3.00 \\
(0.82)\end{array}$ & $\begin{array}{l}\text { 9. Help users recognize } \\
\text { diagnose and recover } \\
\text { from errors }\end{array}$ & $\begin{array}{l}3.50 \\
(0.58)\end{array}$ \\
\hline $\begin{array}{l}\text { 2.Match between system } \\
\text { and real world }\end{array}$ & $\begin{array}{l}3.50 \\
(1.29)\end{array}$ & $\begin{array}{l}\text { 10. Help and } \\
\text { documentation }\end{array}$ & $\begin{array}{l}3.25 \\
(1.26)\end{array}$ \\
\hline $\begin{array}{l}\text { 3. User control and } \\
\text { freedom }\end{array}$ & $\begin{array}{l}4.00 \\
(1.15)\end{array}$ & $\begin{array}{l}\text { 11. Selection driven } \\
\text { commands }\end{array}$ & $\begin{array}{l}3.75 \\
(1.26)\end{array}$ \\
\hline $\begin{array}{l}\text { 4. Consistency and } \\
\text { standards }\end{array}$ & $\begin{array}{l}3.75 \\
(1.26)\end{array}$ & $\begin{array}{l}\text { 12. Content } \\
\text { organization }\end{array}$ & $\begin{array}{l}3.75 \\
(1.26)\end{array}$ \\
\hline $\begin{array}{l}\text { 5. Error prevention } \\
\text { 13. Visual } \\
\text { representation }\end{array}$ & $\begin{array}{l}4.25 \\
(0.50)\end{array}$ \\
\hline $\begin{array}{l}\text { 6. Recognition rather } \\
\text { than recall }\end{array}$ & $\begin{array}{l}4.00 \\
(0.82)\end{array}$ & 14. Behaviour change & $\begin{array}{l}4.75 \\
(0.50)\end{array}$ \\
\hline $\begin{array}{l}\text { 7. Flexibility and } \\
\text { efficiency of use }\end{array}$ & $\begin{array}{l}(0.75 \\
(0.50)\end{array}$ & 15. Self-monitoring & $\begin{array}{l}4.00 \\
(0.82)\end{array}$ \\
\hline $\begin{array}{l}\text { 8. Aesthetic and } \\
\text { minimalist design }\end{array}$ & $\begin{array}{l}4.00 \\
(0.82)\end{array}$ & & \\
\hline
\end{tabular}

\section{Usability Questionnaire (UQ)}

The usability questionnaire assessment was scored with "somewhat agree" to "agree" across all three components. (Tables IV, V, and VI). The average for "Ease of use", "Interface and satisfaction", and "Usefulness" scored 5.80/7.0, 5.57/7.0, and 5.83/7.0, respectively.

The "Ease of Use" scored highest among the three domains denotes that the app has simplicity in its design (Table IV). These results concluded that the KEPT app was easy and useful among pregnant women with several modifications needed to specific interfaces, especially the organization of the 
information and acknowledgement from the app when the users completed their tasks (Table V). The experts agreed that KEPT app was a useful app in behavioral changes and healthcare services as listed in Table VI.

The least scores were: (1) The information in the app was well organized, so I could easily find the information I needed; (2) Whenever I made a mistake using the app, I could recover easily and quickly; and (3) I could use the app even when the Internet connection was poor or not available.

TABLE IV. EASE OF USE

\begin{tabular}{|c|l|l|}
\hline & MAUQ: Ease of Use & Mean (SD) \\
\hline 1. & The app was easy to use. & $5.75(0.96)$ \\
\hline 2. & It was easy for me to learn to use the app. & $5.50(1.29)$ \\
\hline 3. & $\begin{array}{l}\text { The navigation was consistent when moving between } \\
\text { screens. }\end{array}$ & $6.00(0.82)$ \\
\hline 4. & $\begin{array}{l}\text { The interface of the app allowed me to use all the } \\
\text { functions (such as entering information, responding to } \\
\text { reminders, viewing information) offered by the app. }\end{array}$ & $6.25(0.96)$ \\
\hline 5. & $\begin{array}{l}\text { Whenever I made a mistake using the app, I could } \\
\text { recover easily and quickly. }\end{array}$ & $5.50(1.29)$ \\
\hline
\end{tabular}

1 - strongly disagree, 2 - disagree, 3 - somewhat disagree, 4 - neither agree nor disagree, 5 - somewhat agree, 6 - agree, 7 - strongly agree

TABLE V. INTERFACE AND SATISFACTION

\begin{tabular}{|c|l|l|}
\hline & MAUQ: Interface and satisfaction & Mean (SD) \\
\hline 1 & I like the interface of the app & $6.25(0.50)$ \\
\hline 2 & $\begin{array}{l}\text { The information in the app was well organized, so I } \\
\text { could easily find the information I needed }\end{array}$ & $5.00(1.41)$ \\
\hline 3 & $\begin{array}{l}\text { The app adequately acknowledged and provided } \\
\text { information to let me know the progress of my action. }\end{array}$ & $5.25(1.50)$ \\
\hline 4 & I feel comfortable using this app in social settings. & $5.50(1.29)$ \\
\hline 5 & $\begin{array}{l}\text { The amount of time involved in using this app has been } \\
\text { fitting for me. }\end{array}$ & $5.50(0.58)$ \\
\hline 6 & I would use this app again. & $5.75(0.50)$ \\
\hline 7 & Overall, I am satisfied with this app. & $5.75(1.26)$ \\
\hline 1 - strongly disagree, 2 - disagree, 3 - somewhat disagree, 4- neither agree nor disagree, 5- somewhat
\end{tabular}
agree, 6 - agree, 7 - strongly agree

TABLE VI. USEFULNESS

\begin{tabular}{|l|l|l|}
\hline & MAUQ: Usefulness & Mean (SD) \\
\hline 1 & The app would be useful for my health and well-being. & $6.25(0.96)$ \\
\hline 2 & The app improved my access to healthcare services. & $5.75(0.96)$ \\
\hline 3 & The app helped me manage my health effectively. & $6.00(0.82)$ \\
\hline 4 & $\begin{array}{l}\text { This app has all the functions and capabilities I expected it } \\
\text { to have. }\end{array}$ & $6.00(0.82)$ \\
\hline 5 & $\begin{array}{l}\text { I could use the app even when the Internet connection was } \\
\text { poor or not available. }\end{array}$ & $5.00(2.71)$ \\
\hline 6 & $\begin{array}{l}\text { This mHealth app provides an acceptable way to receive } \\
\text { healthcare services, such as accessing educational } \\
\text { materials, tracking my own activities, and performing } \\
\text { self-assessment. }\end{array}$ & $6.00(1.41)$ \\
\hline
\end{tabular}

1 - strongly disagree, 2 - disagree, 3 - somewhat disagree, 4 - neither agree nor disagree, 5 - somewhat agree, 6 - agree, 7 - strongly agree
From these assessments, the team suggested with list of improvements such as, (1) to arrange the interface according to the user's daily PFMT activities and monitoring steps; (2) to explain the "undo" icon; and (3) to inform to the users that the app can functioned without the internet access. They need the internet connection only when submitting the questionnaires.

\section{DISCUSSION}

This study investigated the usability of a newly usercentered PFMT app designed and developed for pregnant women with urinary incontinence. Three types of usability assessment used were the cognitive walkthrough, heuristic evaluation, and usability questionnaire. There were a few difficulties in learning of the KEPT app for example, the organization of the information, and the PFMT interface whereby the users are expected to perform three times daily. This usability evaluation was able to assist the researchers to improve the app's design for better acceptability and usability in the KEPT app prototype for its pilot study [30].

The main objective for the KEPT app was to provide opportunities to pregnant women with UI to perform PFMT at their own convenience. It was crucial to ensure pregnant women have the confidence and understanding of the importance of PFMT especially so when they are experiencing UI. Studies reported that pregnant women face few barriers from either their own misunderstanding, lack of knowledge, lack of support from their partners and from the healthcare providers $[6,7,31]$.

There were several key findings which could be divided into the learnability using the app, the elements of its user interface, and the usability issues of the app.

1) Learnability of the app: Most of the assessors were concerned about the organization of the apps and its training mode function. Poor organization of the app with lack of user manual to inform what the function of the icon and how the app works interfered with the understandability of using the app.

User manual was important to provide an overview of the app and the guidance using the app. Similarly, a mHealth app related with self-managing chronic heart failure among elderly reported that they appreciated having an instruction user manual prior to using the apps [32]. However, not all users used the instruction manual to understand the apps as some of them preferred to try a few times and be able to understand the functionality of the app [33]. Nevertheless, by having a manual it provided advantages to the users an option to read for better understanding of the app even to the professional users [34]. Hence, to improve the understanding of KEPT apps, a user's manual will be added at the top right corner for the users' better accessibility.

Another major concern by the experts was the lack of clarity in the training mode. The poor visibility of each icon and its function disrupt the understanding of the PFMT process. Clarity is crucial in understanding the functionality of the app especially when it involves behavioral change, for example apps for exercise or physical training. Lack of clarity will affect the user's understanding and further perceive it to be 
difficult. Perceived ease of use has been highlighted by the Technology Acceptance Model (TAM) as the main domain to contribute to the actual use of the app $[35,36]$. Therefore, to ensure the daily use of the apps, the training mode needed to be re-designed for better clarity.

2) User interface of the app: Using heuristic evaluations, the experts who were providing their evaluation on the issues of the problematic user interface, were also supplementing their suggestions in their report. The insightful feedback was gathered, and further discussion will be made to improve the user interface system design for better clarity and ease of use by the users.

Another finding was the consistency using the Malay language in the KEPT app to better be understood by the users was highlighted. Consistency is one of the ten heuristic elements by Nielsen [15]. Without consistency, the flow of the app was disturbed and causing frustration to the users. Being difficult in understanding about the app leading to perceived lack of usefulness and affecting the user's attitude and behavior to use the app (TAM). Hence, the future KEPT app must have a consistency using Malay language throughout the apps.

The user interface for training was lack of clarification. There was no indicator to signal to the users on their current repetition out of ten for each set of PFMT. The expert suggests making it visible by proportion of the total set. Another major issue, they faced difficulty in understanding the training interface to be setting according to the user's PFMT ability. Therefore, their suggestions were to ensure the training mode interface is easy to understand, with the indicator showing the user's current exercise. The design needs to be simple, zero interruption, and able to record the data to the backend system without any disruption.

3) Usability of the app: The KEPT app was evaluated with "somewhat agree" in terms of its easy to use, good interface and satisfactory and useful as the overall overview. This signified that KEPT app development has proved its importance and could possibly improve the user's PFMT after its actual use in future. The usability questionnaire results confirmed the finding from $\mathrm{CW}$ and HE. Positive feedback from the result was that it scored high in its usefulness. This signals that the app might be able to improve the PFMT adherence among pregnant women through daily usage.

Therefore, the key findings when developing a mobile health (mHealth) app for pregnant women with an incontinence can be listed as the manual instruction for the users is crucial, the training interface should be designed with simplicity, and Malay language to be used throughout all the UI. Additionally, the arrangement of the icon interface should be arranged according to the users' daily activities for better systematic organization.

This usability assessment has limitation such as the session was conducted individually and not face to face with the researcher. The session was due to the restriction movement order that hinder the researcher to meet the experts. Hence, there could be issues due to technical problem such as incompatibility of the application with Android devices.

\section{CONCLUSION}

The KEPT app was developed to educate incontinent pregnant women to perform PFMT. This paper aimed to evaluate the usability properties of the app from the experts' point of view. KEPT app should be design with an efficiency, effective, and provides the users with the required information. Firstly, by conducting the cognitive walkthrough to understand and analyze the ability of the app to make the users complete their task. Next, heuristic evaluation which assessing the user interfaces available in the KEPT app conform with certain important guidelines for better usability properties.

Finally, the usability questionnaire evaluation conducted with the experts showed encouraging findings of its ease of use, interface and satisfaction, and usefulness. Nevertheless, the usability assessment indicated that a few interfaces of the KEPT app need to be improved. The organization of the interfaces, consistent Malay language usage, and system design for the training interface need to be improved according to the recommendations.

Few necessary iterations will be conducted to re-design the application prior to this usability evaluation. This study was the first usability evaluation PFMT mHealth app for pregnant women found in the literature and to the best of our knowledge such a study has not been conducted. The next step is to develop the KEPT app by improving the usability problems which were highlighted and suggested from the experts.

We hope that the findings in this study will be of assistance to other researchers in their future studies in developing the PFMT mHealth app.

\section{ACKNOWLEDGMENT}

The authors thanked the team of experts for their contributions in evaluating the KEPT app comprehensively. This research was supported and funded by the Geran Putra Berimpak Universiti Putra Malaysia (UPM/8003/3/1/GPB/2018/9668500).

\section{REFERENCES}

[1] Abrams P, Andersson K, Apostolidis A, Birder L, Bliss D, Brubaker L, et al. 6th International Consultation on Incontinence. Recommendations of the International Scientific Committee: evaluation and treatment of urinary incontinence, pelvic organ prolapse and faecal incontinence. Neurourol Urodyn. 2018;37(7):2271-2272.

[2] Moossdorff-Steinhauser HFA, Berghmans BCM, Spaanderman MEA, Bols EMJ. Prevalence, incidence and bothersomeness of urinary incontinence in pregnancy: a systematic review and meta-analysis. Int Urogynecol J. 2021;32(7):1633-1652. PMID: 31229999.

[3] Jaffar A, Mohd-Sidik S, Abd Manaf R, Foo CN, Gan QF, Saad H. Quality of life among pregnant women with urinary incontinence: A cross-sectional study in a Malaysian primary care clinic. Rosier PFWM, editor. PLoS One. Public Library of Science; 2021;16(4):e0250714.

[4] Jaffar A, Mohd-Sidik S, Nien FC, Fu GQ, Talib NH. Urinary incontinence and its association with pelvic floor muscle exercise among pregnant women attending a primary care clinic in Selangor, Malaysia. Rosier PFWM, editor. PLoS One. Public Library of Science; 2020;15(7):e0236140.

[5] Moossdorff-Steinhauser HFA, Berghmans BCM, Spaanderman MEA, Bols EMJ. Urinary incontinence during pregnancy: prevalence, experience of bother, beliefs, and help-seeking behavior. Int Urogynecol J. 2021;32(3):695-701. PMID: 33078344.

[6] Woodley SJ, Hay-Smith EJC. Narrative review of pelvic floor muscle training for childbearing women-why, when, what, and how. Int 
Urogynecol J. International Urogynecology Journal; 2021;7-10. PMID: 33950309.

[7] Terry R, Jarvie R, Hay-Smith J, Salmon V, Pearson M, Boddy K, et al. "Are you doing your pelvic floor?" An ethnographic exploration of the interaction between women and midwives about pelvic floor muscle exercises (PFME) during pregnancy. Midwifery. 2020;83:102647. PMID: 32014618

[8] Chen X, Wang Y, Tao D, Jiang L, Li S. Antecedents of smartphone multitasking: roles of demographics, personalities and motivations. Internet Res. 2021;31(4):1405-1443.

[9] Iribarren SJ, Akande TO, Kamp KJ, Barry D, Kader YG, Suelzer E. Effectiveness of Mobile Apps to Promote Health and Manage Disease: Systematic Review and Meta-analysis of Randomized Controlled Trials. JMIR mHealth uHealth. 2021;9(1):e21563. PMID: 33427672.

[10] Woodley SJ, Lawrenson P, Boyle R, Cody JD, Mørkved S, Kernohan A, et al. Pelvic floor muscle training for preventing and treating urinary and faecal incontinence in antenatal and postnatal women. Cochrane Database Syst Rev. 2020;2020(5). PMID: 32378735.

[11] Ren S, Gao Y, Yang Z, Li J, Xuan R, Liu J, et al. The effect of pelvic floor muscle training on pelvic floor dysfunction in pregnant and postpartum women. Phys Act Heal. Ubiquity Press; 2020;4(1).

[12] Wang X, Xu X, Luo J, Chen Z, Feng S. Effect of app-based audio guidance pelvic floor muscle training on treatment of stress urinary incontinence in primiparas: A randomized controlled trial. Int J Nurs Stud. England: Elsevier Ltd; 2020;104:103527. PMID: 32058140.

[13] Peischl B, Ferk M, Holzinger A. The fine art of user-centered software development. Softw Qual J. 2015;23(3):509-536.

[14] Holzinger A, Searle G, Kleinberger T, Seffah A, Javahery H. Investigating Usability Metrics for the Design and Development of Applications for the Elderly BT - Computers Helping People with Special Needs. In: Miesenberger K, Klaus J, Zagler W, Karshmer A, editors. Berlin, Heidelberg: Springer Berlin Heidelberg; 2008. p. 98105.

[15] Nielsen J. Usability inspection methods. Conf companion Hum factors Comput Syst - CHI '94. New York, New York, USA: ACM Press; 1994. p. 413-414.

[16] Shareef S, Khan MNA. Evaluation of Usability Dimensions of Smartphone Applications. Int J Adv Comput Sci Appl. 2019;10(9):426431.

[17] Hornbæk K, Law EL-C. Meta-analysis of correlations among usability measures. Proc SIGCHI Conf Hum factors Comput Syst. 2007. p. 617626.

[18] Overdijkink SB, Velu A V., Rosman AN, van Beukering MDM, Kok M, Steegers-Theunissen RPM. The Usability and Effectiveness of Mobile Health Technology-Based Lifestyle and Medical Intervention Apps Supporting Health Care During Pregnancy: Systematic Review. JMIR mHealth uHealth. 2018;6(4):e109. PMID: 29691216.

[19] Nielsen J, Molich R. Heuristic evaluation of user interfaces. Conf Hum Factors Comput Syst - Proc. 1990;(April):249-256.

[20] Beauchemin M, Gradilla M, Baik D, Cho H, Schnall R. A Multi-step Usability Evaluation of a Self-Management App to Support Medication Adherence in Persons Living with Hiv. Int J Med Inform. Elsevier; 2019;122(August 2018):37-44. PMID: 30623782.

[21] Pruitt J, Adlin T. The persona lifecycle: keeping people in mind throughout product design. Elsevier; 2006.
[22] Kumar BA, Mohite P. Usability guideline for mobile learning apps: an empirical study. Int J Mob Learn Organ. Inderscience Publishers (IEL); 2016;10(4):223.

[23] Kumar BA, Goundar MS. Usability heuristics for mobile learning applications. Educ Inf Technol. Education and Information Technologies; 2019;24(2):1819-1833.

[24] Khowaja K, Al-Thani D. New Checklist for the Heuristic Evaluation of mHealth Apps (HE4EH): Development and Usability Study. JMIR mHealth uHealth. JMIR Publications; 2020;8(10):e20353.

[25] Brooke J. Sus: a "quick and dirty'usability. Usability Eval Ind. 1996;189.

[26] Lewis JR. Psychometric evaluation of the PSSUQ using data from five years of usability studies. Int J Hum Comput Interact. Taylor \& Francis; 2002;14(3-4):463-488.

[27] Zhou L, Bao J, Setiawan IMA, Saptono A, Parmanto B. The mHealth App Usability Questionnaire (MAUQ): Development and Validation Study. JMIR mHealth uHealth. 2019;7(4):e11500.

[28] Lewis JR. Psychometric Evaluation of the Post-Study System Usability Questionnaire: The PSSUQ. Proc Hum Factors Soc Annu Meet. 1992;36(16):1259-1260.

[29] Witteman HO, Vaisson G, Provencher T, Chipenda Dansokho S, Colquhoun H, Dugas M, et al. An 11-Item Measure of User- and Human-Centered Design for Personal Health Tools (UCD-11): Development and Validation. J Med Internet Res. 2021;23(3):e15032. PMID: 33724194.

[30] Jaffar A, Mohd Sidik S, Foo CN, Muhammad NA, Abdul Manaf R, Fadhilah Ismail SI, et al. Protocol of a Single-Blind Two-Arm (Waitlist Control) Parallel-Group Randomised Controlled Pilot Feasibility Study for mHealth App among Incontinent Pregnant Women. Int J Environ Res Public Health. 2021;18(9):4792.

[31] Perera J, Kirthinanda DS, Wijeratne S, Wickramarachchi TK. Descriptive cross sectional study on prevalence, perceptions, predisposing factors and health seeking behaviour of women with stress urinary incontinence. BMC Womens Health. 2014;14(1):78. PMID: 24985068.

[32] Morey SA, Barg-Walkow LH, Rogers WA. Managing heart failure on the Go: Usability issues with mHealth apps for older adults. Proc Hum Factors Ergon Soc. 2017;2017-Octob:1-5.

[33] Loh KP, Ramsdale E, Culakova E, Mendler JH, Liesveld JL, O’Dwyer $\mathrm{KM}$, et al. Novel mHealth App to Deliver Geriatric Assessment-Driven Interventions for Older Adults With Cancer: Pilot Feasibility and Usability Study. JMIR Cancer. 2018;4(2):e10296. PMID: 30373733.

[34] Saparamadu AADNS, Fernando P, Zeng P, Teo H, Goh A, Lee JMY, et al. User-Centered Design Process of an mHealth App for Health Professionals: Case Study. JMIR mHealth uHealth. 2021;9(3):e18079. PMID: 33769297.

[35] Nadal C, Sas C, Doherty G. Technology acceptance in mobile health: Scoping review of definitions, models, and measurement. J Med Internet Res. 2020;22(7):1-17. PMID: 32628122.

[36] Binyamin SS, Zafar BA. Proposing a mobile apps acceptance model for users in the health area: A systematic literature review and metaanalysis. Health Informatics J. SAGE Publications Ltd; 2021;27(1):1460458220976737. 